\title{
FAMILIAL DIFFUSE PROGRESSIVE ENCEPHALOPATHY
}

\author{
BY
}

\author{
M. C. LIU and PETER E. SYLVESTER \\ From the Fountain Hospital, London
}

(RECEIVED FOR PUBLICATION OCTOBER 21, 1959)

The purpose of this paper is to present the clinical and neuropathological findings in two idiot brothers in whom the mode and time of onset and the pattern of brain anomalies were remarkably similar. Clinically there were similarities with well-known syndromes such as Tay Sachs and Schilder's disease. However, the ultimate diagnosis was to emphasize the frequent difficulties encountered in determining the aetiology of mental deficiency with progressive neurological features.

\section{Family History}

The parents, each an only child, were English and in good health. There was no history of consanguinity, mental illness, epilepsy, ataxia, blindness, skeletal deformity or other neurological disease in three generations of the family.

\section{Case Histories}

Case 1. This child, the first, was born when the father was 29 years old and the mother 28 . The mother attended an antenatal clinic and, after seven months gestation, developed hydramnios. Pregnancy was otherwise normal as far as is known and the baby was born at full term. The presentation was occipito-posterior, labour was prolonged, and the child was delivered by forceps. No asphyxia was noted at birth but the child's head was bruised. The birth weight was $9 \mathrm{lb} .3 \mathrm{oz}$. $(4,160$ g.). He was regarded as normal until 3 weeks old, when epileptiform movements were noticed on several occasions. At 6 weeks these movements started again. They consisted of a spasmodic twitching of the neck to the rightit, and of the left arm and leg, and increased in severity to involve the whole body, which became straight and rigid with the head and eyes deviated to the left and the face becoming red. To begin with he had between two and four such attacks a day but this became increasingly more frequent until he was having between seven and 10 or more, despite treatment with phenobarbitone.

Initially, he was breast fed but at 7 weeks increasing difficulty with sucking made it necessary to substitute spoon feeding. Up to this time he had been considered a normal child mentally and physically, apart from the seizures. From then on he deteriorated and at the age of 3 months he was described as lying helpless and barely able to move his limbs. He never smiled and appeared to be blind. By the age of 3 years and 2 months he was described as inert, silent, helpless and drowsy all day. He was unable to sit up and could move only his right leg slightly. He failed to respond to any stimuli except painful ones which provoked a monotonous scream. He was deaf and speech had not developed. Feeding was difficult because of the extreme slowness in swallowing. He suffered from severe constipation. Mentation and behaviour were such that both were described as 'less than that of a new born child'. He had no grasp reflex and his developmental quotient was zero.

Clinical Findings. On admission to the Fountain Hospital he weighed $10.6 \mathrm{~kg}$., height $84.2 \mathrm{~cm}$. (normal for age and sex is $14.61 \mathrm{~kg}$., height $96 \cdot 7 \mathrm{~cm}$.).

At 3 months old his head was markedly asymmetrical, though its circumference $(45 \cdot 1 \mathrm{~cm}$.) was slightly larger for age (normal: $40.9 \mathrm{~cm}$.). At 3 years 2 months the circumference $(49.5 \mathrm{~cm}$.) was still within normal limits (normal: $50.4 \mathrm{~cm}$.), but the asymmetry was more marked. The left frontal region had become very prominent and there was left occipital bossing. His teeth were yellowish. A spastic paralysis was more marked on the left side, especially the leg. There was a right facial weakness, the right palpebral fissure being wider than the left and the movements of the muscles of the forehead and the right side of the mouth being diminished. Contractures of the wrist flexors were present, the hand being flexed at the metacarpophalangeal and extended at the interphalangeal joints. A severe thoracolumbar scoliosis and talipes equino-val us was observed. Babinski's sign was positive on both sides and the knee and other tendon jerks were exaggerated while the abdominal reflexes were absent. A light bilateral rotary nystagmus was also noted. The optic discs were atrophic, the edges being clear, cut. Vessels of the fundi and the maculae were normal.

On the ninth day after admission to the Fountain Hospital he developed bronchopneumonia. He died 16 days later, at the age of 3 years and 2 months.

INVESTIGATIONS. C.S.F. examinations showed no abnormality and W.R. and Kahn tests were negative. An air encephalogram revealed internal hydrocephalus.

Pathological Findings. The necropsy, on the day 
after death, was done by the Coroner's pathologist. The cause of death was acute suppurative bronchopneumonia.

The fixed brain, asymmetrical due to the right hemisphere being slightly larger than the left, with the cerebellum and brain stem, weighed $915 \mathrm{~g}$. (average normal for age is $1,141 \mathrm{~g}$.). Radiographically, the ventricles were moderately distended; there was no evidence of calcification. The meninges over the frontal lobes and tips of the temporal lobes were opaque and congested. The superior and middle frontal, and the superior precentral sulci, were widened. The surface of the uncus was finely granular; the entire corpus callosum was very thin, being only $1 \mathrm{~mm}$. thick in its thinnest part. The basal ganglia looked normal. There were widespread fine ependymal granulations of the lateral ventricular walls. The optic nerves were small and at the chiasma were $2.5 \times 1.5 \mathrm{~mm}$. (normal $4.7 \mathrm{~mm}$. (Duke-Elder, 1932)), but other cranial nerves and the vessels at the base of the brain were normal.

Histological Findings. Coronal sections of the frontal, parietal and occipital lobes, the basal ganglia with temporal lobes, the mid brain, pons, medulla and cerebellum were embedded in celloidin and sections stained by the usual neuropathological proceduresNissl, Heidenhain, H.V.G., Mallory's P.T.A.H. and Holzer. Paraffin and frozen sections were used when necessary for the Holzer, Kultschitzky-Pal, Bielchowsky, Turnbull and Scarlet $\mathbf{R}$ methods.

There were conspicuous structural changes in the cerebral hemispheres. Nerve cells were sparse in all regions of the cortex, being most marked in layer III. Surviving cells appeared normal in size and shape. Status spongiosus affected some cortical areas at the level of layer III. Perigyral gliosis was marked in the frontal, parietal and occipital lobes and to a much less extent around the uncus. Apart from shallow undulations of the surface of the uncus and this slight gliosis, there was no histological explanation such as granular atrophy to account for the curious naked eye granular appearances of the part.

The white matter in the parietal, temporal and occipital lobes was abnormally pale in sections stained by myelin techniques. Higher magnifications revealed various stages of degeneration of the myelin sheaths and breakdown such as tortuosity, focal ballooning, varicosity, uneven staining and beading. Astrocytes were increased throughout the white matter and there was a fine reticular fibrous gliosis in the corona radiata and the central core of white matter of the gyri of the frontal, parietal, temporal and occipital regions; it was densest in the tapetum. Lipid phagocytes were confined locally in a scanty fashion to the vicinity of blood vessels. There were no areas of localized softenings, tissue breakdown and cyst formation in the white matter. The arcuate fibres were involved to an equal extent with other white fibre tracts.

The thalamus, striatum and pallidum appeared to have a normal number of healthy looking cells and a normal amount of white matter. Fibrous gliosis was absent. Similarly the corpus Luysii and red nucleus were healthy.

Comparison of the mid brain section at the level of the superior corpora quadrigemina with a similar section

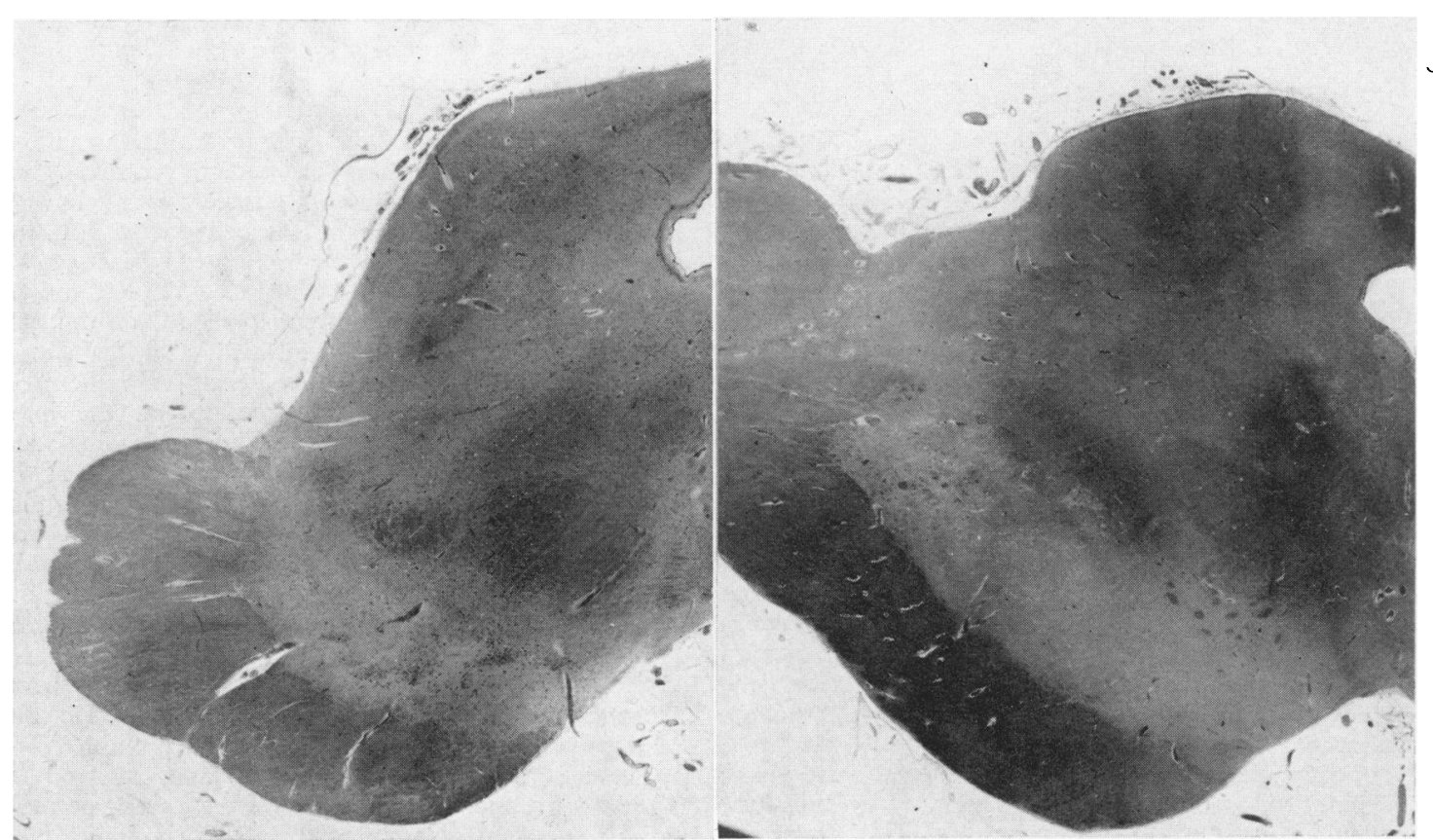

FIG. 1a.-Case 1, paucity of cells in the substantia nigra of one half of the mid-brain. H.V.G. $\times 6$.
FIG. 1b.-Case 2, absence of cells in the substantia nigra. H.V.G. $\times 6$. 


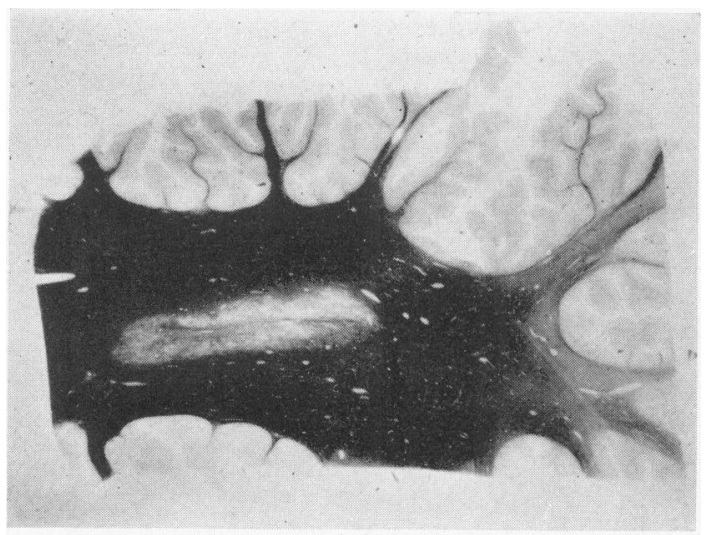

FIG. 2.

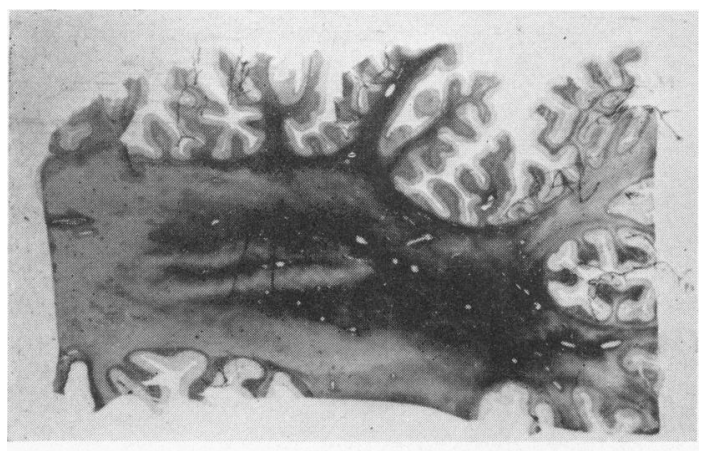

FIG. 3. from a control brain (a child aged 18 months) revealed definite sparseness of nerve cells in the substantia nigra. Those cells present lacked pigment, a normal finding at this age, and were in three or four scattered groups (Fig. 1a). Status spongiosus affected the area. In other parts of the brain stem there was a normal complement of healthy looking cells in the olives pontine and cranial nerve nuclei. The pyramids were small and pale. Fibrous gliosis was present in the inferior olives and in their central core of white matter, hila and white fibres around their convolutions. A fine diffuse network of glial fibres was present throughout the reticular formation.

Periventricular gliosis was increased around the dilated ventricles. The ependyma was absent in places and replaced by ependymal granulations - $a$ feature most marked in the fourth ventricle.

Cellular components of the cerebellum were fewer in numbers than normal. This was most obvious in the dentate nucleus but Purkinje and granular cells were also reduced in numbers. Pallor of the myelin was present in the central core of white matter of the dentate nucleus, and medullary white matter of the cerebellum and the central core of the folia and leaflets (Fig. 2). There were large globules up to $70 \mu$ in diameter around several blood vessels which stained with the myelin stain. All parts of the cerebellum exhibited fibrous gliosis with an increase of glial cells; for instance, there were reticulated masses of fibres in the medullary white matter and folia (Fig. 3), and in the molecular, Purkinje and granular cell layers there were focal areas of perpendicular gliosis (Fig. 4).

The optic nerves were demyelinated and composed of a network of glial fibres surrounding lacunae from which the myelin sheaths had disappeared.
Fig. 2.-Case 1, pallor of the cerebellar white matter. KultschitzkyPal $\times 2 \frac{1}{2}$

FIG. 3.-Case 1, gliosis of the cerebellar white matter. Holzer $\times 2 \frac{1}{2}$.

FIG. 4.- Case 1, foci of perpendicular gliosis in the molecular, Purkinje cell and granular cell layer caused puckering of the surface of the folia. Mallory's P.T.A.H. $\times 100$.
FIG. 4.

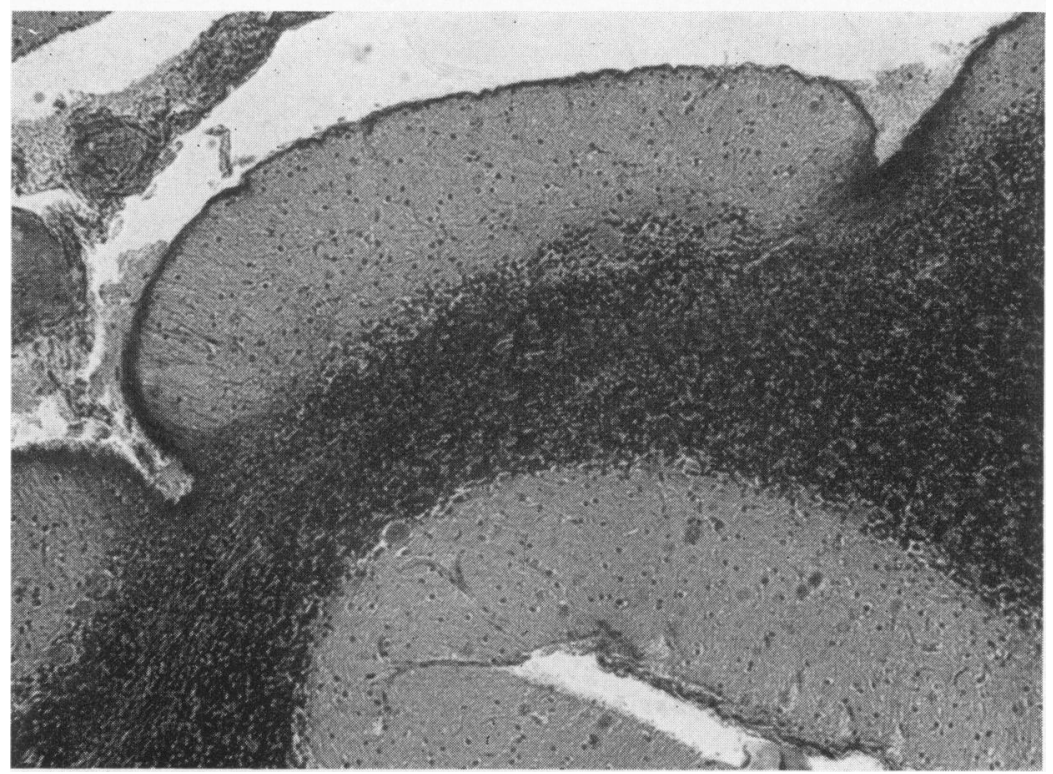


Pia arachnoid vessels were congested. A fine picrophilic deposit was present under the pia in places. The pia arachnoid was thickened and fibrosed over the frontal region, but in other cases the membranes were normal.

Clear lacunae were present around many blood vessels, especially those in the grey matter and brain stem. In several instances similar spaces were filled by a fine picrophilic substance.

There was no evidence of lipoidosis, abnormal pigmentation or calcification.

Case 2.-Pregnancy was apparently normal, the child being delivered by caesarean section just before labour began. This operation was performed at the mother's request to avoid a possible birth injury - to which the elder brother's condition had been attributed. The birth weight was $8 \mathrm{lb} .15 \mathrm{oz}$. (4,040 g.). Discharge from the hospital was on the 21st day, normal progress apparently having occurred. At 7 weeks, he was admitted to hospital because he had started having epileptic seizures. They were tonic in type beginning with suddin jerks of the limbs after which the whole body stiffened. The face became cyanosed and frothing of the mouth occurred. These seizures persisted with increasing frequency and were triggered off by the slightest stimuli, especially during feeds. As in his brother, phenobarbitone seemed to have no effect on the course of the fits. Feeding difficulties were also present, and he suffered from severe constipation.

He was regarded as a normal baby up to 7 weeks old when the fits started. After that mental deficiency gradually became more and more obvious and by the time he was admitted to the Fountain Hospital at 15 months, he was a gross idiot. He lay inert in bed, in a sleep-like state most of the time. He appeared to be blind and was probably deaf, though he was thought to respond to the sound of a bell by momentarily widening his eyes and blinking. He failed to respond to any stimuli except painful ones to which he reacted by crying in a faint monotone. He was unable to suck, having to be fed slowly with a spoon; he had no grasp reflex and his developmental quotient was scored as less than one month, i.e. a little better than that of the elder brother.

Clinical Findings. On admission to the Fountain Hospital he weighed $10 \mathrm{~kg}$., height $75 \mathrm{~cm}$. (normal for age and sex is $10.75 \mathrm{~kg}$. and height $78.5 \mathrm{~cm}$.). The head circumference was $45 \cdot 6 \mathrm{~cm}$. (normal for age and sex is $48 \mathrm{~cm}$.).

At 7 weeks his head was noticed to be asymmetrical. The right side of the skull had a steeper contour than the left and the anterior fontanelle had closed by 15 months. The nose was flat and the eyes were slit-like. No teeth had erupted. His extremities resembled those of a young infant. The thumbs were flexed firmly within the palms of the hands. He was unable to hold up his head, to sit up or perform any other coordinated movements. The muscle tone was slightly increased. The Babinski sign was present bilaterally, though all the tendon jerks and abdominal reflexes were reported absent. His testicles were undescended (as was the case with the elder brother).

On the eighth day after admission to the Fountain Hospital, he suddenly collapsed with severe dyspnoea, with a high fever and signs of bronchopneumonia. $\mathrm{He}$ died two hours later, at the age of 16 months.

INVESTIGATIONS. At 7 weeks skull radiograph was normal. Subdural explorations revealed no haematoma. The optic discs were pale. C.S.F., serum chlorides and W.R. were all normal.

Pathological Findings. The necropsy on the third day after death was performed by the Coroner's pathologist. Death was due to bronchopneumonia.

The fixed brain, asymmetrical due to the right hemisphere being slightly larger than the left, with the cerebellum and brain stem weighed $807 \mathrm{~g}$. (average normal for age is $\mathbf{9 4 4}$ g.). Radiographically, the lateral ventricles were moderately distended; there was no evidence of calcification. The meninges were congested but not opaque. The superior frontal, superior precentral and cingulate sulci were widened. The corpus callosum was thinner than normal throughout its length; its mid part was $1 \mathrm{~mm}$. thick. The surface of the uncus, as in the brother, was finely granular (Fig. 5). The basal

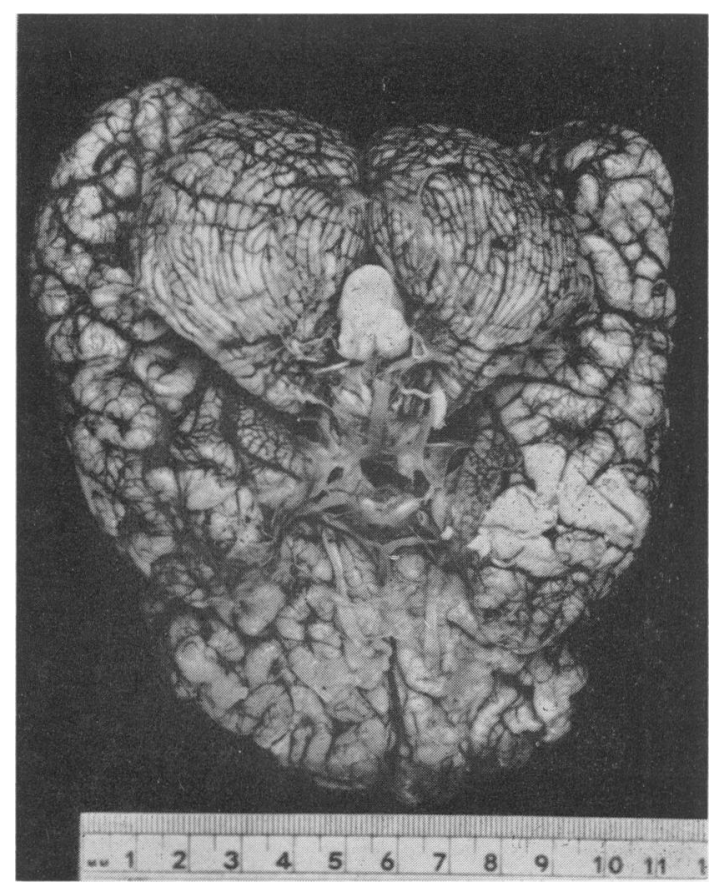

FIG. 5.-Case 2, the granular appearance of the surface of each uncus accentuated by a network of vessels.

ganglia appeared to be normal size. The ependyma was smooth. The optic nerves were small and at their approach to the chiasma were $2.75 \times 2.0 \mathrm{~mm}$. (normal 4 to $7 \mathrm{~mm}$. (Duke-Elder, 1932)). The other cranial 
nerves were normal and vessels at the base of the brain were normal.

Histological Findings. Coronal sections were prepared and stained as for Case 1. The findings in the cerebrum, brain stem, cerebellum and optic nerves were very similar to those of the brother, although there were some differences, notably in the extent of damage in the two cases.

The substantia nigra of Case 2 was more severely affected than Case 1 (Fig. 1b). Nerve cells were almost completely absent and those which remained were degenerated ghost forms. Unlike Case 1, similar changes to those in the substantia nigra were present in the corpus luysii. There was a condensation of dense glial tissue around the putamen of Case 2 (Fig. 6) in whose brain stem all parts were more gliosed than in the brother. Gliosis was particularly dense in the trapezoid bodies, the grey part of the reticular formation, the XII nerve nucleus, and in and around the inferior olives. Cerebellar involvement was less than in Case 1, for instance, the molecular, Purkinje and granular cell layers had escaped gliosis, although their numbers were reduced. The dentate nucleus and white matter were diseased

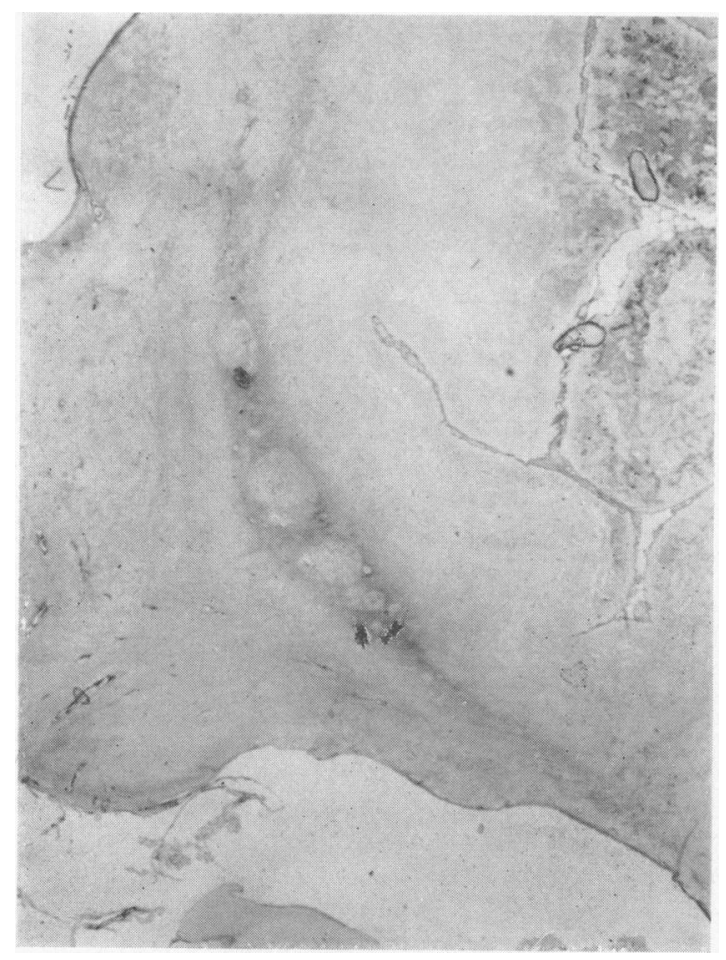

FIG. 6.-Case 2, glial tissue around the putamen. Holzer $\times 5$.

in a similar manner to Case 1 . Case 2 had no ependymal granulations, although periventricular gliosis was increased. The meninges were nowhere thickened. There was apparently less histological evidence to explain the curious naked eye appearances of the granularity to the surface of the uncus since perigyral gliosis was much less than in Case 1. The surface was definitely more undulant than usual and the hollows were occupied by congested meningeal vessels, otherwise the architectonics were quite normal.

\section{Discussion}

Cases bearing some similarity to these brothers have been described by Alpers (1931) and called 'diffuse progressive degeneration of the grey matter of the cerebrum'; Christensen and Krabbe (1949) who called their case 'poliodystrophia cerebri progressiva (infantalis)', and Ford, Livingston and Pryles (1951) who called the condition 'familial degeneration of the cerebral grey matter in childhood'. Wolf and Cowen (1956) included a case under the heading 'diffuse progressive cerebral cortical atrophy'. Their principal findings are listed in the Table.

Convulsions, the earliest clinical manifestations in our cases, commenced at 3 weeks (Case 1) and 7 weeks (Case 2) and were earlier in onset than those of other observers. It was possible that the illness occurred prenatally in Case 1 since hydramnios was associated with intra-uterine life from the seventh month. This accords with a view expressed by Christensen and Krabbe (1949) who thought that the disorganization of the cortical cellular layers in their case was congenital in origin although they could not exclude the possibility that it may have been a consequence of later degeneration.

Ataxia and choreo-athetoid movements present in some of the reported cases (see Table) were absent in the brothers. This was possibly due to the widespread lesions masking the expected clinical features.

Despite the patients' failure to pass any developmental milestones, there were features that the disease was progressive, borne out by the fits becoming more frequent and severe, increasing drowsiness and increasing paralysis of the limbs. This conformed with the findings of Christensen and Krabbe (1949) who found a series of features indicating postnatal progressive processes.

Birth trauma was an unlikely cause of the condition, especially in view of the extra care taken to prevent this in Case 2, and the lack of supporting pathological features such as ulegyria (cortical atrophy) and état marbré (marbling) the cause of which is often attributed to birth injury. Slight meningeal thickening and some ependymal granulations in Case 1 suggested an infective cause, but both these features were absent in the other child. Since the lesions in the two brains were so similar in other respects, it was felt that the basic cause of the 
TABLE

COMPARISON OF CASES

DISEASES TO BE CONSIDERED IN THE DIAGNOSIS OF THE TWO PRESENTED CASES

\begin{tabular}{|c|c|c|c|c|}
\hline Authors & $\begin{array}{l}\text { No. of } \\
\text { Cases } \\
\text { Reported }\end{array}$ & $\begin{array}{l}\text { Age } \\
\text { at } \\
\text { Onset }\end{array}$ & Clinical Features & Neuropathological Findings \\
\hline $\begin{array}{l}\text { Alpers, } 1931 \\
\text { Diffuse progiessive degenera- } \\
\text { tion of the grey matter of the } \\
\text { cerebrum }\end{array}$ & 1 & 3 months & $\begin{array}{l}\text { Convulsions, hyperkinesis, generalized } \\
\text { rigidity, increased tendon reflexes, } \\
\text { unable to hold up her head, died at } \\
5 \text { months }\end{array}$ & $\begin{array}{l}\text { Defective cortical development, neuronal } \\
\text { degeneration and astrocytic proliferation } \\
\text { in cortex, striatum, pallidum and } \\
\text { thalamus, cerebellum spared }\end{array}$ \\
\hline $\begin{array}{l}\text { Christensen and Krabbe, } 1949 \\
\text { Poliodystrophia cerebri progres- } \\
\text { sive (infantilis) }\end{array}$ & 1 & 8 months & $\begin{array}{l}\text { Delayed milestones and mental retarda- } \\
\text { tion and gradual deterioration of both } \\
\text { mental and physical conditions } \\
\text { Increasing spasticity and myoclonic } \\
\text { contractions, abnormal tendon reflexes, } \\
\text { paresis and ataxia, optic atrophy and } \\
\text { probably deaf and dumb, dental ano- } \\
\text { malies up to four generations, died at } \\
2 \frac{1}{2} \text { years }\end{array}$ & $\begin{array}{l}\text { Cerebral atrophy with secondary } \\
\text { increase in microglia, whereas white } \\
\text { matter was fairly well preserved, similar } \\
\text { findings in basal ganglia, cerebellum } \\
\text { and brain stem }\end{array}$ \\
\hline $\begin{array}{l}\text { Ford, Livingston and Pryles, } 1951 \\
\text { Familial degeneration of the } \\
\text { grey matter in childhood }\end{array}$ & 4 & $\begin{array}{l}\text { Cases } 1 \\
\text { and } 2 \\
6 \text { years } \\
\text { Case } 3 \\
6 \text { months } \\
\text { Case } 4 \\
4 \text { years }\end{array}$ & $\begin{array}{l}\text { Mental retardation, epileptic fits, myo- } \\
\text { tonic and choreo-athetoid movements, } \\
\text { increasing spasticity, hemiplegia and } \\
\text { progressive dementia. } \\
\text { Cases } 1 \text { and } 2 \text { were sister and brother } \\
\text { and maternal uncle died in status } \\
\text { epilepticus }\end{array}$ & $\begin{array}{l}\text { Cortical atrophy, destruction of neu- } \\
\text { rones, proliferation of astrocytes, micro- } \\
\text { glia and capillary proliferation and } \\
\text { secondary myelin loss. Thalamus, corpus } \\
\text { subthalamicum and substantia nigra, } \\
\text { striatum, cerebellar cortex and dentate } \\
\text { nuclei were degenerated }\end{array}$ \\
\hline $\begin{array}{l}\text { Wolf and Cowen, } 1956 \\
\text { Diffuse progressive cerebral } \\
\text { cortical atrophy }\end{array}$ & 8 & $\begin{array}{l}3 \text { months } \\
\text { to } \\
2 \text { years }\end{array}$ & $\begin{array}{l}\text { Epileptic seizures, spasticity, mental } \\
\text { retardation, blindness and spastic } \\
\text { quadriplegia }\end{array}$ & $\begin{array}{l}\text { Cerebral atrophy with loss of nerve } \\
\text { cells; thalamus, cerebellum, corpus } \\
\text { striatum, caudate and dentate nuclei and } \\
\text { putamen affected } \\
\text { (Some degeneration of posterior-column } \\
\text { and spino-cerebellar tracts in spinal } \\
\text { cord in one case) }\end{array}$ \\
\hline Presented cases & 2 & At birth & $\begin{array}{l}\text { Fits, blindness, hypertonus, nystagmus } \\
\text { Babinski response variable, idiocy early } \\
\text { in onset }\end{array}$ & $\begin{array}{l}\text { Paucity of nerve cells in cortical grey } \\
\text { matter, cerebellum and substantia nigra. } \\
\text { Pallor of myelin corona radiata and } \\
\text { cerebellum. Fibrous gliosis around } \\
\text { inferior olivary nuclei, in tegmentum } \\
\text { and in Case } 2 \text { around lentiform nucleus. } \\
\text { Optic nerves pale and gliosed. }\end{array}$ \\
\hline
\end{tabular}

lesions had some other origin with perhaps secondary infection complicating Case 1; however, this was not proved during life by clinical investigations.

Two of the cases described by Ford et al. (1951) were half-sibs (brother and sister). Malamud and Cowen (1958) described findings in two male first cousins which they regarded as an unusual form of cerebellar ataxia transmitted by sex linked inheritance. Only one case was examined pathologically and features similar to some of those of the brothers were described, for instance, gliosis of the cerebellar folia, dentate nucleus, inferior olives, basal ganglia and optic tracts.

An appraisal of the clinical and pathological evidence and that of the reported cases suggested that the lesions in these brothers were probably determined prenatally. It was felt that genetic factors may be an important influence; though there was no proof of this, however, it would concur with our view from experience that there may be several forms of mental deficiency other than well-known conditions such as phenylketonuria, amaurotic idiocy and so forth, which may be caused by genetic factors.
'Degeneration of the cerebral grey matter', part of the descriptive name used by Alpers (1931), Christensen and Krabbe (1949), Ford et al. (1951) and Wolf and Cowen (1956) was too limiting in view of the changes in the cerebral white matter, the brain stem and cerebellum, and it seemed more appropriate, if the disease is the same, to call the condition familial diffuse progressive encephalopathy in childhood.

\section{Summary}

A disorder involving a diffuse progressive encephalopathy occurred in two brothers, beginning in the first possibly before birth and in the second around the time of birth.

A family study failed to reveal similar cases.

The main clinical features consisted of progressive mental deterioration, epileptic fits and increasing spasticity and paralysis. Both children became deaf and blind. Apart from slight nystagmus, there were no involuntary movements or other signs of a cerebellar disorder. Kyphoscoliosis and equino varus were present in both. 
The principal neuropathological features were paucity of nerve cells in cortical grey matter, cerebellum and substantia nigra. There was pallor of myelin in the corona radiata and the cerebellum. Fibrous gliosis was present around the inferior olivary nuclei, in the tegmentum and in one case around the lentiform nucleus. The optic nerves were pale and gliosed.

Norms of weight, height and head circumference are quoted from Studies of Child Health and Development, Harvard School of Public Health, in Nelson's 'Textbook of Pediatrics', Philadelphia, 1959.

We are indebted to Drs. L. T. Hilliard and L. Crome, and many other colleagues at the Fountain Hospital for their help and advice.

\section{REFERENCES}

Alpers, B. J. (1931). Diffuse progressive degeneration of the gray matter of the cerebrum. Arch. Neurol. Psychiat. (Chicago), 25, 469.

Christensen, E. and Krabbe, K. H. (1949). Poliodystrophia cerebri progressiva (infantalis). Ibid., 61, 28

Duke-Elder, W. S. (1932). Textbook of Ophthalmology, Vol. 1, p. 102. Kimpton, London.

Ford, F. R., Livingston, S. and Pryles, C. V. (1951). Familial degeneration of the cerebral gray matter in childhood. $J$. Pediat., 39, 33

Malamud, N. and Cohen, P. (1958). Unusual form of cerebellar ataxia with sex-linked inheritance. Neurology, 8, 261.

Wolf, A. and Cowen, D. (1956). The cerebral atrophies and encephalomalacias of infancy and childhood. In Neurology and Psychiatry in Childhood, Res. Publ. Ass. nerv. ment. Dis., Vol. 34, p. 199. 